\title{
Ocorrência de Euglenophyceae pigmentadas em rizipiscicultura na Região do Vale do Itajaí, SC, Sul do Brasil
}

\author{
Sandra Maria Alves-da-Silva ${ }^{1,3}$ e Márcio da Silva Tamanaha ${ }^{2}$
}

Recebido em 11/08/2005. Aceito em 15/05/2007

\begin{abstract}
RESUMO - (Ocorrência de Euglenophyceae pigmentadas na rizipiscicultura na região do Vale do Itajaí, SC, Sul do Brasil). O estudo de uma amostra oriunda do cultivo de arroz irrigado (Oriza sativa L.) associado com criação de carpa comum (Cyprinus carpio Linnaeus, 1758), em um ambiente raso ( $20 \mathrm{~m}^{2} \times 0,30 \mathrm{~m}$ de prof.), na Região do Vale do Itajaí, Santa Catarina (2653’33”S, 04849'41 ”W), resultou na identificação de 48 morfoespécies da classe Euglenophyceae, representados pelos gêneros Euglena, Lepocinclis, Phacus, Strombomonas e Trachelomonas. O gênero Trachelomonas foi o que apresentou o maior número de táxons (26\%). Destacou-se Euglena caudata Hübner e Euglena sanguinea Ehr. pelo elevado número de indivíduos por lâmina. Vinte e oito táxons são primeiras citações de ocorrência para o estado de Santa Catarina. São fornecidas descrições, chaves dicotômicas, dimensões, relação entre o comprimento e a largura celular (Rc/l), ilustrações dos táxons e distribuição geográfica mundial.
\end{abstract}

Palavras-chave: cultivo de arroz, fitoplâncton, Euglena sanguinea, Itajaí, Sul do Brasil

\begin{abstract}
Occurrence of pigmented Euglenophyceae in rice-fish fields of the Itajaí River Valley region, Santa Catarina State, southern Brazil). A sample collected from rice-fish fields (Oriza sativa L. and Cyprinus carpio Linnaeus, 1758) in shallow water ( $20 \mathrm{~m}^{2} \times 0.30 \mathrm{~m}$ deep) in the Itajai River Valley region, Santa Catarina (26 53'33"'S and 48 $\left.49^{\prime} 41^{\prime \prime} \mathrm{W}\right)$ revealed 48 morphospecies from the class Euglenophyceae represented by the genera Euglena, Lepocinclis, Phacus, Strombomonas and Trachelomonas. Trachelomonas was the best represented genus with $26 \%$ of all taxa. The reddish water at the time of sampling was due to the high number of Euglena caudata Hübner and Euglena sanguinea Ehr. individuals per plate (bloom). Twenty eight taxa are new records for the state of Santa Catarina. Descriptions, dichotomous keys, size variation, length/width relationship (Rc/l), illustrations and geographic distribution are provided for all taxa.
\end{abstract}

Key words: rice fields, phytoplankton, Euglena sanguinea, Itajaí, southern Brazil

\section{Introdução}

No sul do Brasil, o arroz irrigado é uma cultura de destaque, onde ocupa cerca de um milhão de hectares, nos estados do Rio Grande do Sul e Santa Catarina, área que fornece aproximadamente $50 \%$ da produção nacional de cereal. O método de cultivo é através da utilização de sementes pré-germinadas, semeadas a lanço em solo coberto por uma lâmina de água, além do controle de pragas com a aplicação de pesticidas (Epagri 1998). A cultura do arroz irrigado tem grande importância social e econômica para o Estado de Santa Catarina, tendo uma safra 2002/2003, de 134 mil hectares em mais de 60 municípios, com uma produção superior a um milhão de toneladas (Noldin et al. 2003).
A cultura de arroz irrigado é considerada como um agroecossistema que apresenta uma alta produtividade biológica e a comunidade planctônica apresenta um papel relevante exercendo importantes funções na fixação e reciclagem de nutrientes (Roger et al. 1991). Contudo, a sua alteração através da manipulação humana com o propósito de estabelecer uma produção agrícola, torna-o muito diferente dos ecossistemas naturais.

Para atenuar a degradação dos ecossistemas através da produção agrícola com a utilização de herbicidas, inseticidas e fungicidas, experimentos com métodos alternativos têm sido realizados no intuito de verificar a possível diminuição do impacto ambiental destes produtos. Um dos métodos comumente utilizados

\footnotetext{
1 Museu de Ciências Naturais da FZB/RS, Av. Salvador França, 1427, Bairro Jardim Botânico, C. Postal 1188, 90690-000 Porto Alegre, RS, Brasil

2 Universidade do Vale do Itajaí, Centro de Ciências Tecnológicas da Terra e do Mar, Rua Uruguai, 458, C. Postal 360, 88302-202 Itajaí, SC, Brasil (mt@univali.br; mstamanaha@gmail.com)

3 Autor para correspondência: alvesdasilva@fzb.rs.gov.br; salvesilva5@yahoo.com.br
} 
é a rizipiscicultura (cultivo de arroz associado com peixes).

Durante o projeto "Impacto de práticas de cultivo de arroz irrigado sobre organismos aquáticos", numa parceria entre a Empresa de Pesquisa Agropecuária e Extensão Rural de Santa Catarina S.A. (Epagri Estação Experimental de Itajaí, SC) e Universidade do Vale do Itajaí (UNIVALI/CTTMar), com o apoio da Fundagro, tendo seu início em novembro/2001, foi constatada a presença de freqüentes natas avermelhadas na superfície da água resultante de floração de Euglena sanguinea Ehr. no qual se realizava um experimento de campo semeado com arroz (Oriza sativa L.) e indivíduos de carpa comum (Cyprinus carpio Linnaeus, 1758).

Florações desta espécie foram relatadas em ambientes rasos, tanques de peixes ou em cultivo de arroz por Xavier et al. (1991), Heckman et al. (1993), Pereira et al. (2000), Furtado \& De Luca (2003), Mainardes-Pinto \& Mercante (2003) e Tamanaha (2004, dados não publicados), entre outros autores.

Para o Estado de Santa Catarina existem escassos trabalhos envolvendo euglenoficeas (Tavares 1980; 1981; Laudares-Silva, dados não publicados; Goulart et al. 2002 e Tamanaha, dados não publicados).

O presente estudo objetiva incrementar o conhecimento deste grupo de algas em Santa Catarina e no país, sendo pioneiro em ambiente com cultivo de arroz consorciado com criação de peixes no Brasil.

\section{Material e métodos}

A amostra foi coletada em novembro/2003 com frasco de $500 \mathrm{~mL}$ na porção subsuperficial da água, na qual apresentava uma "mancha avermelhada", durante um experimento de campo com parcelas de $20 \mathrm{~m}^{2}$ e aproximadamente $30 \mathrm{~cm}$ de profundidade. Nestas parcelas foi semeado arroz (Oriza sativa), e introduzidos 100 indivíduos juvenis de carpa comum (Ciprinus carpius). O experimento foi realizado no município de Ilhota, Vale do Itajaí, Santa Catarina, localizado a $26^{\circ} 53^{\prime} 33^{\prime \prime} \mathrm{S}$ e $48^{\circ} 49^{\prime} 41^{\prime \prime} \mathrm{W}$ (Fig. 1).

Parte da amostra foi conservada viva e parte foi fixada com formaldeído $4 \%$ encontrando-se depositado no Herbário Prof. Dr. Alarich R. H. Schultz (HAS) do Museu de Ciências Naturais da Fundação Zoobotânica do Rio Grande do Sul, sob o número HAS 104.853. A análise do material foi realizada sob lâmina e lamínula com auxílio do microscópio LEICA, Mod. DMLS com ocularmicrometrada e os desenhos foram executados com

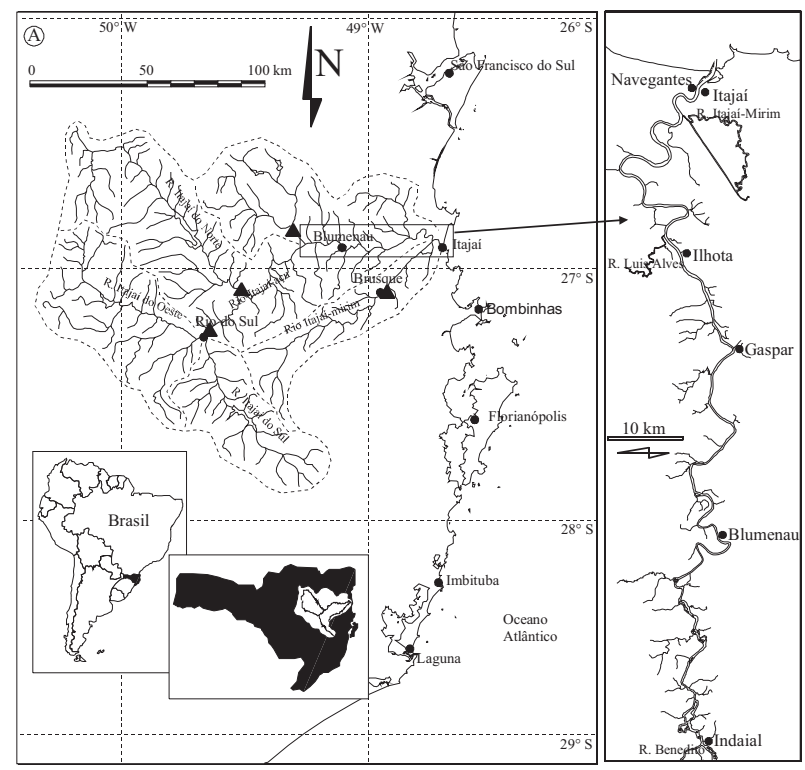

Figura 1. Localização do Vale do Rio Itajaí, município de Ilhota, SC, Brasil, onde foi realizada a amostragem.

auxílio de câmara-clara acoplada ao seu sistema óptico.

O estudo foi baseado em características morfológicas e métricas de populações da natureza. Para a identificação das morfoespécies foram utilizadas obras básicas como: Conrad (1943), Conrad \& Van Meel (1952), Deflandre (1926; 1930), Gojdics (1953), HuberPestalozzi (1955), Németh (1980), Pochmann (1942), Shi et al.(1999), Starmach (1983), Tell \& Conforti (1986), Zakrýs (1986), Weik (1967), Wolowski (1998), além de trabalhos recentes sobre o grupo como Alvesda-Silva \& Bicudo (2002), Alves-da-Silva \& Bridi (2004), Alves-da-Silva \& Hahn (2004), Alves-da-Silva \& Torres (1992), Alves-da-Silva \& Torres (1994), Cecy (1990), Ferreira \& Menezes (2000), Jati \& Train (1994), Menezes $(1989,1990,1991)$, Menezes \& Fernandes (1987), Sant'Anna et al. (1989) e Xavier $(1989 ; 1996)$, entre outros.

São apresentadas descrições das estruturas observadas, variação das dimensões, relação entre o comprimento e a largura celular (Rc/l), ilustração dos táxons, chave de classificação, comentários de alguns táxons e distribuição geográfica mundial.

\section{Resultados e discussões}

A análise de somente uma amostra em que foi observado elevado número de espécimes por lâmina de Euglena sanguinea Ehr. (1.809 ind. $\left.\mathrm{mL}^{-1}\right) \mathrm{e}$ E. caudata Hübner (625 ind. $\left.\mathrm{mL}^{-1}\right)$, permitiu a 
identificação de 48 táxons específicos e infraespecíficos dos gêneros Euglena, Lepocinclis, Phacus, Strombomonas e Trachelomonas, assim distribuídos: 31 espécies, 14 variedades taxonômicas que não as típicas e 3 formas não típicas de suas respectivas variedades. Observou-se que a classe Euglenophyceae esteve bem representada neste ambiente raso, sendo $13 \%$ do gênero Lepocinclis, $19 \%$ de Euglena, 19\% de Strombomonas, 23\% de Phacus e $26 \%$ de Trachelomonas.

\section{Chave artificial para identificação de gêneros de Euglenophyceae pigmentadas}

1. Células loricadas

2. Colarinho sempre presente, sem delimitação precisa do restante da lórica

Strombomonas

2. Colarinho ausente ou, quando presente, com delimitação precisa do restante da lorica

Trachelomonas

1. Células nuas

3. Células com metabolia

Euglena

3. Células sem metabolia

4. Células achatadas Phacus

4. Células não achatadas Lepocinclis

Chave artificial para identificação das espécies e infra-espécies gênero Euglena Ehrenberg 1838.

1. Duplo-pirenóides presentes Euglena caudata var. caudata

1. Pirenóides ausentes

2. Película com estrias longitudinais

3. Com verrugas

4. Verrugas esféricas, célula com 75-85 $\mu \mathrm{m}$ compr., 11-15 $\mu \mathrm{m}$ larg.

4. Verrugas poligonais, célula com 178-199 $\mu \mathrm{m}$ compr., 30-51 $\mu \mathrm{m}$ larg.

Euglena spirogyra var. spirogyra ............................................................................................... Euglena spirogyra var. fusca

3. Sem verrugas

5. Grãos de paramido 2

6. Processo caudal cônico torcido para um dos lados Euglena allorgei var. allorgei

6. Processo caudal não torcido Euglena oxyuris var. charkowiensis

5. Grãos de paramido superior a 2

7. Célula com 88-90 $\mu$ m compr., 7-9 $\mu$ m larg., grãos de paramido em número de 4-7

7. Célula com 259-262 $\mu \mathrm{m}$ compr., 9-11 $\mu \mathrm{m}$ larg., grãos de paramido em número superior a 7 Euglena acus var. longissima

2. Película com estrias espiraladas

8. Com grânulos de hematocromo Euglena sanguinea var. sanguinea

8. Sem grânulos de hematrocromo Euglena viridis var. viridis

1. Euglena acus Ehr. var. acus, Infusions. Organismen. 112, pl. 7, fig. 15. 1838.

Fig. 2

Células fusiformes, 88-90 $\mu \mathrm{m}$ compr., 7-9 $\mu \mathrm{m}$ larg., Rc/1 = 11,2-12,6; pólo posterior atenuado em processo caudal hialino, cônico, 10-12 $\mu$ m compr.; película rígida a semi-rígida, estrias longitudinais, às vezes ausentes; cloroplastos numerosos, discóides, 1,8-2,5 $\mu \mathrm{m}$ diâm.; pirenóides ausentes; grãos de paramido 4-7 bastoniformes, ca. de $11 \times 3 \mu \mathrm{m}$; flagelo ca. de $0,5 \mathrm{vez}$ o comprimento da célula.
Distribuição geográfica: cosmopolita.

2. Euglena acus Ehr. var. longissima Defl., Revue algol., 1(3): 238, pl. 4, fig. 1-3. 1924a.

Fig. 3

Células fusiformes, 259-262 $\mu \mathrm{m}$ compr., 9-11 $\mu \mathrm{m}$ larg., Rc/l = 23,5-29.

Distribuição geográfica: cosmopolita.

Comentários: a variedade difere da típica pelas maiores dimensões celulares. Esta variedade freqüentemente ocorre associada a espécie típica. 
3. Euglena allorgei Defl. var. allorgei, Bull. Soc. Bot. Fr., 24: 116, fig. 1-2. 1924b.

Fig. 4

Células fusiformes, 106,4-111,0 $\mu \mathrm{m}$ compr., 14-16,5 $\mu \mathrm{m}$ larg., Rc/1 = 6,7-7,2; pólo posterior gradativamente atenuado, terminando abruptamente em processo caudal hialino, cônico, voltado para um dos lados, 12-16,5 $\mu \mathrm{m}$ compr.; película granulosa, rígida a semi-rígida, estrias longitudinais; cloroplastos numerosos, discóides, parietais, 3,5-3,7 $\mu \mathrm{m}$ compr.; pirenóides ausentes, grãos de paramido 2, bastoniformes, 23,5-25,4 $\mu \mathrm{m}$ compr., um anterior, o outro posterior ao núcleo; núcleo central.

Distribuição geográfica: América do Norte, América do Sul, Europa.

4. Euglena caudata Hübner var. caudata, Progr. Realgymn. Stralsund, p. 5, fig. 5. 1886.

Fig. 5-6

Células fusiformes, 92-98 $\mu \mathrm{m}$ compr., 14-17 $\mu \mathrm{m}$ larg., $\mathrm{Rl} / \mathrm{l}=5,4-6,3$; pólo posterior atenuado em processo caudal hialino, cônico, 8 m compr.; película com estrias helicoidais; cloroplastos numerosos, discóides, lisos ou com margens lobuladas, cada um com duplo-pirenóides; grãos de paramido numerosos, pequenos, ovais ou discóides; flagelo ca. 0,5 vez o comprimento da célula.

Distribuição geográfica: cosmopolita.

Comentários: a espécie apresenta movimento intenso, com forte metabolia na região anterior da célula o que dificulta sua identificação.

5. Euglena oxyuris Schmarda var. charkoviensis (Swir.) Chu, Sinensia 17(1/6): 95. 1946.

Fig. 7

Células fusiformes, 142-147 $\mu \mathrm{m}$ compr., 18,5-20 $\mu \mathrm{m}$ larg., $\mathrm{Rc} / 1$ = 7,3-7,9; pólo posterior atenuado em processo caudal hialino, cônico, $24 \mu \mathrm{m}$ compr.; película semi-rígida, estrias acompanhado a torção da célula; cloroplastos numerosos, discóides, parietais, 2,5 $\mu \mathrm{m}$ diâm.; grãos de paramido 2, bastoniformes, $22 \mu \mathrm{m}$ de compr., $9 \mu \mathrm{m}$ de larg., um anterior e outro posterior ao núcleo oblongo central; flagelo ca. uma vez o comprimento da célula.

Distribuição geográfica: cosmopolita.

Comentários: difere da variedade típica da espécie pelas menores dimensões celulares.

6. Euglena sanguinea Ehr. var. sanguinea, Abh. Berl. Akad. Wiss. Physik aus d. Jahre 1831, Berlin, p. 71.1832 .

Fig. 8-9
Células amplamente fusiformes a fusiformes,

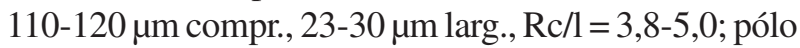
posterior atenuado em processo caudal hialino, cônico; cloroplastos alongados, radialmente arranjados; grãos de paramido amplamente elípticos; grânulos de hematocromos numerosos, distribuídos em toda a superfície da célula; flagelo ca. de uma vez o comprimento celular.

Distribuição geográfica: cosmopolita.

Comentários: Euglena sanguinea tem sido citada por vários autores como uma espécie que, quando em floração, pode conferir coloração avermelhada a água. Esta coloração deve-se à presença de grânulos de hematocromo na célula da alga, que aumentam rapidamente em quantidade sob condições de estresse como altas temperaturas e luminosidade. Os espécimes vivos apresentaram intensa metabolia, mudando sua forma de fusiforme a arredondada rapidamente. Sua identificação à primeira vista é facilitada pela presença de grânulos vermelhos de hematocromo distribuídos em toda extensão da célula. Esta espécie junto com outras como Euglena paludosa Mainx 1926; E. rubida Mainx 1928; E. purpurea Mainx 1926; E. haematodes (Ehr.) Lemm. 1913 e E. rubra Hardy 1911, entre outras, formam um complexo de espécies com hematocromo.

$O$ rápido deslocamento de $E$. sanguinea graças a um flagelo longo, sua mudança na forma para arredondada e presença de muitos grãos de hematocromo dificulta sobremaneira a visualização e representação das estruturas internas diagnósticas da espécie como cloroplastos, paramidos e estrias.

7. Euglena spirogyra Ehr. var. fusca Klebs, Unters. Bot. Inst. Tübingen, 1: 77. 1883.

Fig. 10

Células cilíndricas, 178-199 $\mu \mathrm{m}$ compr., 30-51 $\mu \mathrm{m}$ larg., $\mathrm{Rc} / \mathrm{l}=4,0-6,0$.

Distribuição geográfica: cosmopolita.

Comentários: esta variedade difere da típica pelas maiores dimensões, pelas verrugas poligonais e coloração mais escura da película (castanhaavermelhada).

8. Euglena spirogyra Ehr. var. spirogyra, Abh. Berl. Akad. Wiss. Physik aus d. Jahre 1830, Berlin, p. 83, (1832).

Fig. 11

Células cilíndricas, 75-85 $\mu \mathrm{m}$ compr., 11-15 $\mu \mathrm{m}$ larg., Rc/l = 5,3-6,2; pólo anterior arredondado; pólo 
posterior atenuado abruptamente em processo caudal até $10 \mu \mathrm{m}$ compr.; película amarelada a amarronzada com verrugas hemisféricas entre as estrias, cloroplastos discóides, numerosos; grãos de paramido 2, bastoniformes, 12-17 $\mu$ m compr., 5-7 $\mu \mathrm{m}$ larg., núcleo central oblongo.

Distribuição geográfica: cosmopolita.

Comentários: esta variedade é facilmente reconhecida pela presença de verrugas hemisféricas entre as estrias.

9. Euglena viridis Ehr. var. viridis, Infus. 107, pl. 7, fig. 9. 1838.

Fig. 12
Células amplamente fusiformes, 40-45 $\mu \mathrm{m}$ compr., 12-15 $\mu \mathrm{m}$ larg., Rc/1 = 3,0-3,2; pólo anterior arredondado; pólo posterior atenuado em processo caudal cônico; película com estrias finas, dextrôgiras; cloroplastos numerosos em fitas radiais, partindo da região central da célula orientadas em diversas direções; grãos de paramido numerosos, arredondados, concentrados na região central da célula; núcleo posterior, arredondado, flagelo ca. de uma vez o comprimento celular.

Distribuição geográfica: cosmopolita.

Comentários: esta espécie é de difícil identificação devido a sua grande mobilidade e metabolia, arqueando a região mediana, dificultando a visualização das estruturas do protoplasto.

Chave artificial para identificação das espécies e infra-espécies de Lepocinclis Perty 1852

1. Película com estrias levógiras, grãos de paramido laterais anelares

2. Célula elíptica

3. Células com 22-23 $\mu \mathrm{m}$ compr., $15 \mu \mathrm{m}$ larg., Rc/l=1,5 Lepocinclis ovum var. dimidio-minor

3. Células com, 35-36 $\mu$ m compr., 16-18 larg., Rc/l.=2,0 Lepocinclis ovum var. ovum

2. Células citrifomes, fusiformes ou rombóides

4. Células citriformes a fusiformes Lepocinclis fusiformis var. fusiformis

4. Células rombóides a pentagonais, pólo anterior truncado Lepocinclis truncata var. truncata

1. Película com estrias dextrógiras, grãos de paramido discóides ou alongados

5. Processo caudal cônico truncado, 3-5 $\mu \mathrm{m}$ de compr.

5. Sem processo caudal. Lepocinclis salina var. salina f. obtusa Lepocinclis salina var. salina

10. Lepocinclis fusiformis (Carter) Lemm. emend. Conr. var.fusiformis, Arch. Protistenk., 82(2): 225, fig. 30. 1934.

Fig. 13

Células citriformes a fusiformes, 23-28 $\mu \mathrm{m}$ compr.; 16-18 $\mu \mathrm{m}$ larg., Rc/l = 1,3-1,6; pólo anterior com mamilo obtuso ou não; pólo posterior levemente acuminado, processo caudal reduzido a mamilo, ca. $1 \mu \mathrm{m}$ compr.; película semi-rígida, hialina; estrias levógiras, tênues; cloroplastos numerosos, discóides ou alongados, ca. de 2,5 $\mu$ m diâm.; grãos de paramido 2, anelares, alongados, laterais; flagelo ca. 0,5 vez o comprimento celular.

Distribuição geográfica: cosmopolita.

11. Lepocinclis ovum (Ehr.) Lemm. var. dimidiominor Defl., Bull. Soc. bot. Fr., 24(4): 1121, fig. 25-28. 1924.

Fig. 14

Células estreitamente-elípticas a elípticas, 22-23 $\mu \mathrm{m}$ compr., $15 \mu \mathrm{m}$ larg., Rc/1 = 1,5.
Distribuição geográfica: África, América do Sul, Ásia e Europa.

Comentários: difere da espécie típica por suas menores dimensões celulares e o processo caudal reduzido a mamilo, com cerca de $1 \mu \mathrm{m}$ de comprimento.

12. Lepocinclis ovum (Ehr.) Lemm. var. ovum, Kryptog. Bradenburg, 3: 504, fig. 13. 1910.

Fig. 15

Células amplamente elípticas, 35-36 $\mu$ m compr., 17-18 $\mu \mathrm{m}$ larg., Rc/l = 2,0; pólo anterior arredondado; vista polar transversal circular; pólo posterior atenuado em processo caudal cônico, ca. de $8 \mu$ m compr.; película com estrias levógiras, finas; cloroplastos discóides, numerosos; grãos de paramido 2, laterais e opostos; flagelo ca. 0,5 vez o comprimento celular.

Distribuição geográfica: cosmopolita.

13. L. salina Fritsch var. salina, New Phytologist, 13: 351, fig. 3a-b, e. 1914.

Fig. 17

Células amplamente elípticas a ovadas, 38-48 $\mu \mathrm{m}$ 

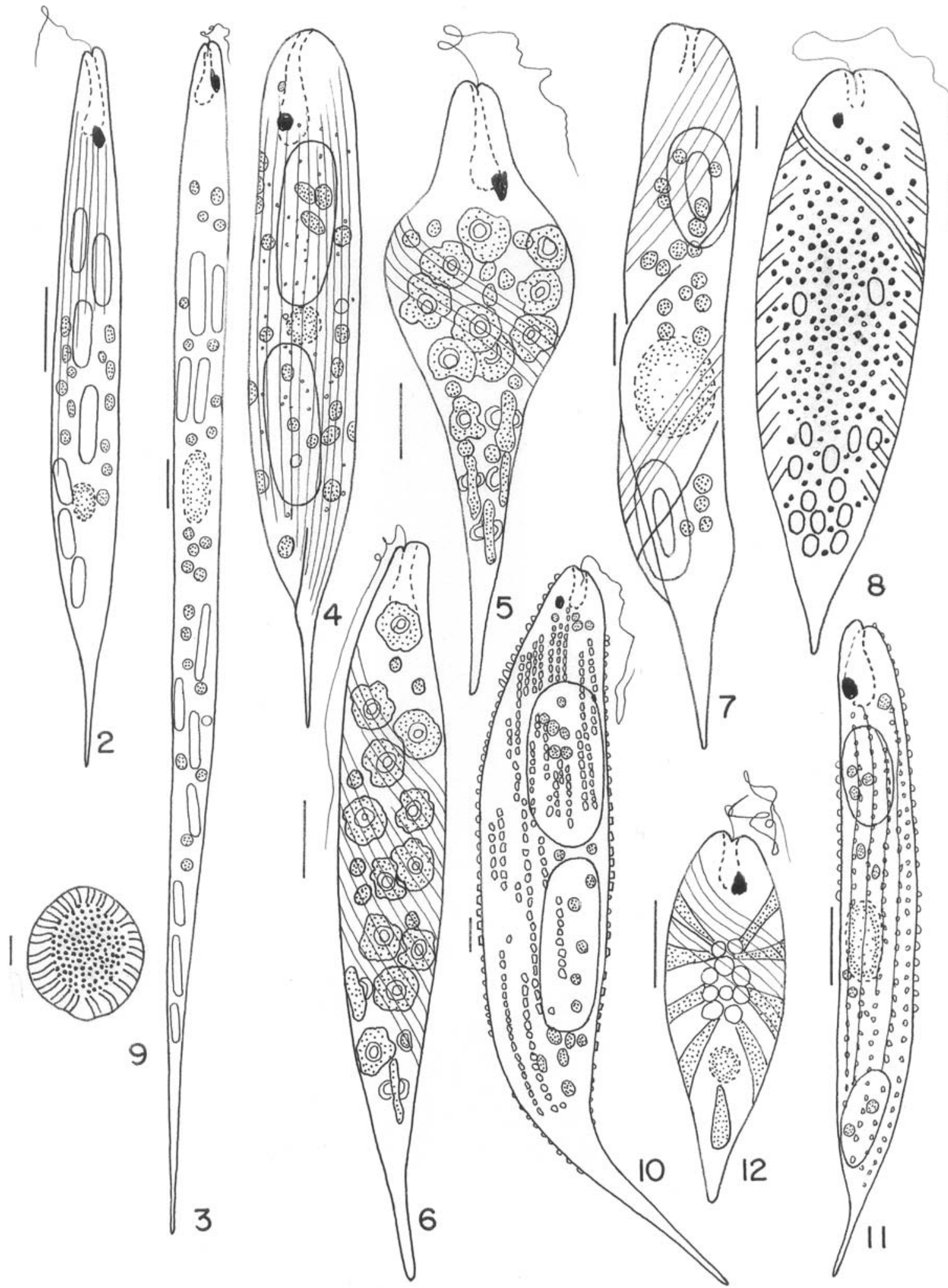

Figuras 2-12. 2. Euglena acus Ehr. var. acus. 3. E. acus Ehr. var. longissima Defl. 4. E. allorgei Defl. var. allorgei. 5-6. E. caudata Hübner var. caudata. 7. E. oxyuris Schmarda var. charkoviensis (Swir.) Chu. 8-9. E. sanguinea Ehr. var. sanguinea. 9. Vista polar. 10. E. spirogyra Ehr. var. fusca Klebs. 11. E. spirogyra Ehr. var. spirogyra. 12. E. viridis Ehr. var. viridis. Barras $=10 \mu \mathrm{m}$. 
compr., 30-38 $\mu \mathrm{m}$ larg., Rc/1 = 1,2-1,3; pólos arredondados; vista polar transversal circular; abertura do canal sub-apical, prolongada em depressão lateral profunda, oblíqua; película rígida, hialina; estrias dextrógiras; cloroplastos numerosos, parietais, discóides, ca. 2,8 $\mu \mathrm{m}$ diâm.; grãos de paramido numerosos, discóides, globosos ou alongados, jamais anelares, 5-7 $\mu \mathrm{m}$ diâm.

Distribuição geográfica: cosmopolita.

14. Lepocinclis salina Fritsch var. salina f. obtusa (Hub.-Pest.) Conr. Mém. Mus. r. Hist. nat. Belg., 2(1): 63, fig. 58. 1935.

Fig. 16

Células amplamente elípticas a ovadas, 37-42 $\mu \mathrm{m}$ compr., 27-30 $\mu$ m larg., Rc/l = 1,3-1,4.

Distribuição geográfica: África, América do Sul.

Comentários: difere da variedade típica da espécie pelo processo caudal cônico-truncado. Goulart et al. (2002) não identificaram este táxon como f. obtusa. Porém a ilustração fornecida nesta obra corresponde a f. obtusa, sendo por esta razão, o segundo registro da forma para Santa Catarina.
15. Lepocinclis truncata Cunha var. truncata, Mem. do Inst. Oswaldo Cruz, 6(3): 170, pl. 24, fig. 1. 1914. Fig. 18

Células rombóides a pentagonais, 40-47 $\mu \mathrm{m}$ compr., 28-35 $\mu \mathrm{m}$ larg., Rc/1 = 1,3-1,5; pólo anterior truncado; pólo posterior acuminado; película rígida, esverdeada, estrias levógiras, finas; cloroplastos discóides, numerosos; grãos de paramido 2, laterais e opostos; flagelo ca. de uma vez o comprimento celular.

Distribuição geográfica: América do Sul, Ásia, Europa.

Comentários: esta espécie foi descrita para o Rio de Janeiro em 1914 por Cunha, sendo este o segundo registro de Lepocinclis truncata para o país, quase um século depois de sua primeira observação. Tell \& Conforti (1986) comentam que Lepocinclis truncata só foi registrado em regiões quentes da Argentina, assim como no Brasil foi primeiramente citado para região tropical. Neste estudo apesar da espécie ter sido encontrada em região subtropical a temperatura era elevada $\left(26,8^{\circ} \mathrm{C}\right)$ no momento da coleta. Este foi o segundo registro da espécie para o país.

Chave artificial para identificação das espécies e infra-espécies do gênero Phacus Dujardin 1841

1. Cloroplastos 2, em forma de escudo Phacus agilis var agilis

1. Cloroplastos numerosos, discóides

2. Processo caudal maior que $25 \mu \mathrm{m}$

3. Células amplamente elípticas, presença de estrias transversais ..........Phacus longicauda var. tortus

3. Células obovadas, ausência de estrias transversais ................... Phacus longicauda var. longicauda

2. Processo caudal menor que $20 \mu \mathrm{m}$

4. Célula torcida

5. Célula dobrada em sela Phacus raciborskii var. raciborskii

5. Célula ovada ou com contorno circular

6. Células divididas em duas porções igual ou diferentemente espessadas Phacus curvicauda var. curvicauda

6. Células divididas em duas porções desiguais, torcidas, a maior expandida posteriormente aliforme, oblíqua Phacus contortus var. contortus

4. Célula não torcida

7. Vista apical triangular ou cupuliforme

8. Células ovado-alargadas, vista apical triangular com ângulos arredondados

Phacus orbicularis var. orbicularis

8. Células ovadas, vista apical cupuliforme Phacus hamatus var. hamatus

7. Vista apical elíptica

9. Células com reentrâncias na margem Phacus undulatus var. undulatus

9. Células sem reentrância na margem

10. Células amplamente ovadas, processo caudal curvo.... Phacus acuminatus var. variabilis 10. Células amplamente elípticas, processo caudal mamilado...... Phacus stokesii var. minor 


\section{Phacus acuminatus Stokes var. variabilis} (Lemm.) Pochm., Arch. Protistenk, 95(2): 143, fig. 32g-h. 1942.

Fig. 19

Células amplamente ovadas a ovadas, 30-31 $\mu \mathrm{m}$ compr., 23-24 um larg.; Rc/1 = 1,2; pólo anterior arredondado, sulco ca. 0,3 vez o comprimento celular; pólo posterior atenuado em processo caudal hialino, levemente curvo, ca. de $3 \mu \mathrm{m}$ compr.; película com estrias longitudinais, seguindo a torção do corpo; cloroplastos numerosos, discóides; grãos de paramido 2, discóides concêntricos e um excêntrico; núcleo posterior.

Distribuição geográfica: América do Norte, América do Sul, Ásia, Europa.

Comentários: esta variedade diferencia-se da típica por apresentar o processo caudal levemente curvo, excêntrico ao eixo longitudinal.

17. Phacus agilis Skuja var. agilis, Acta Horti bot. Univ. Latv., 1: 39, pl. 2, fig. 4 a-g. 1926.

Fig. 20-21

Células amplamente elípticas a elípticas, 13-14 $\mu \mathrm{m}$ compr., 10-10,2 $\mu \mathrm{m}$ larg.; Rc/1 = 1,3-1,4; pólos arredondados; vista polar reniforme; pólo posterior atenuado em processo caudal mamilado; película com estrias levógiras; cloroplastos 2, forma de calota, laterais, grãos de paramido 2, em forma de escudo laterais; flagelo uma vez o comprimento celular.

Distribuição geográfica: América do Norte, América do Sul, Ásia, Europa.

Comentários: Phacus agilis apresenta deslocamento rápido, razão do epiteto recebido. Facilmente reconhecido pela vista polar transversal reniforme, pela localização dos cloroplastos e grãos de paramido laterais e pela pequena dimensão celular.

18. Phacus contortus Bour. var. contortus, Algues d'éau douce Guad., p.177, pl.22, fig. 271-277, 1952. Fig. 22-23

Células assimétricas, ovadas, torcidas, margens diferentemente espessadas, a maior expandida posteriormente, aliforme, oblíqua, 32-34 $\mu \mathrm{m}$ compr., 24-25 $\mu \mathrm{m}$; Rc/l = 1,3-1,4; pólo anterior arredondado, vista polar cuneada, bissulcada; estrias longitudinais; pólo posterior atenuado abruptamente em processo caudal hialino, curvo, ca. de $5 \mathrm{~mm}$ compr.; cloroplastos numerosos, discóides; grãos de grãos de paramido 2 , discóides.

Distribuição geográfica: América Central, América do Sul, Ásia e Europa.
19. Phacus curvicauda Swir. var. curvicauda, Arch. Hydrobiol. Planktonk., 10: 333, pl. 2, fig. 13-16. 1915. Fig. 24-25

Células ovadas assimétricas, torcidas, margens igual ou desigualmente espessadas, 37-39 $\mu \mathrm{m}$ compr., 28-29 $\mu \mathrm{m}$ larg., Rl/b =1,2-1,3; sulco do vértice ca. 0,5 do comprimento da célula; vista polar cuneada de ângulos arredondados ou em halteres; pólo posterior abruptamente atenuado em processo caudal hialino, curvado, 5-6 $\mu \mathrm{m}$ compr.; película hialina, estrias longitudinais seguindo a torção da célula; cloroplastos, numerosos, discóides a bastoniformes, ca. 2 um diâm.; grãos de paramido 2, discóides, tamanhos desiguais.

Distribuição geográfica: cosmopolita.

20. Phacus hamatus Pochm. var. hamatus, Arch. Protistenk., 95(2): 182, fig. 86a-f. 1942.

Fig. 26-27

Células ovadas, 45-47 $\mu \mathrm{m}$ compr., 27-30 $\mu \mathrm{m}$ larg., Rc/1 = 1,5-1,7; pólo anterior arredondado, sulco do vértice $0,5-0,8$ vez o comprimento da célula; vista polar poculiforme; pólo posterior abruptamente atenuado em processo caudal hialino, curvado, cônico,de 7-8 $\mu \mathrm{m}$ compr., lado ventral côncavo, lado dorsal convexo; película rígida, hialina, estrias longitudinais; cloroplastos parietais, numerosos, discóides, ca. 2,5 $\mu$ m diâm.; grão de paramido 1 ou 2, discóides, sobrepostos, centrais, tamanhos diferentes, 12-14 e 5-8 $\mu \mathrm{m}$ diâm.; núcleo posterior.

Distribuição geográfica: América do Norte, América do Sul, Ásia e Europa.

21. Phacus longicauda (Ehr.) Duj. var. longicauda,

Hist. nat. Zoophytes, p. 337, pl. 5, fig. 6. 1841.

Fig. 28

Células obovadas, 75-86 $\mu \mathrm{m}$ compr., 29-33 $\mu \mathrm{m}$ larg.; Rc/l = 2,5-2,9; pólo posterior atenuado abruptamente em processo caudal longo, hialino, ca. $35 \mu \mathrm{m}$ compr.; película com estrias longitudinais, seguindo de torção da célula; cloroplastos numerosos, discóides; grãos de paramido 2 ou mais, centrais, concêntricos, os menores excêntricos distribuídos no citoplasma; núcleo posterior; flagelo 0,5 vez o comprimento celular.

Distribuição geográfica: cosmopolita.

22. Phacus longicauda (Ehr.) Duj. var. tortus Lemm., Kryptogamenfl. Mark Brandenburg, 3: 511. 1910. Fig. 29

Células ovadas a amplamente elípticas, 66-67 $\mu \mathrm{m}$ compr., 32-33 $\mu \mathrm{m}$ larg.; Rc/l = 2, torcidas uma volta na 


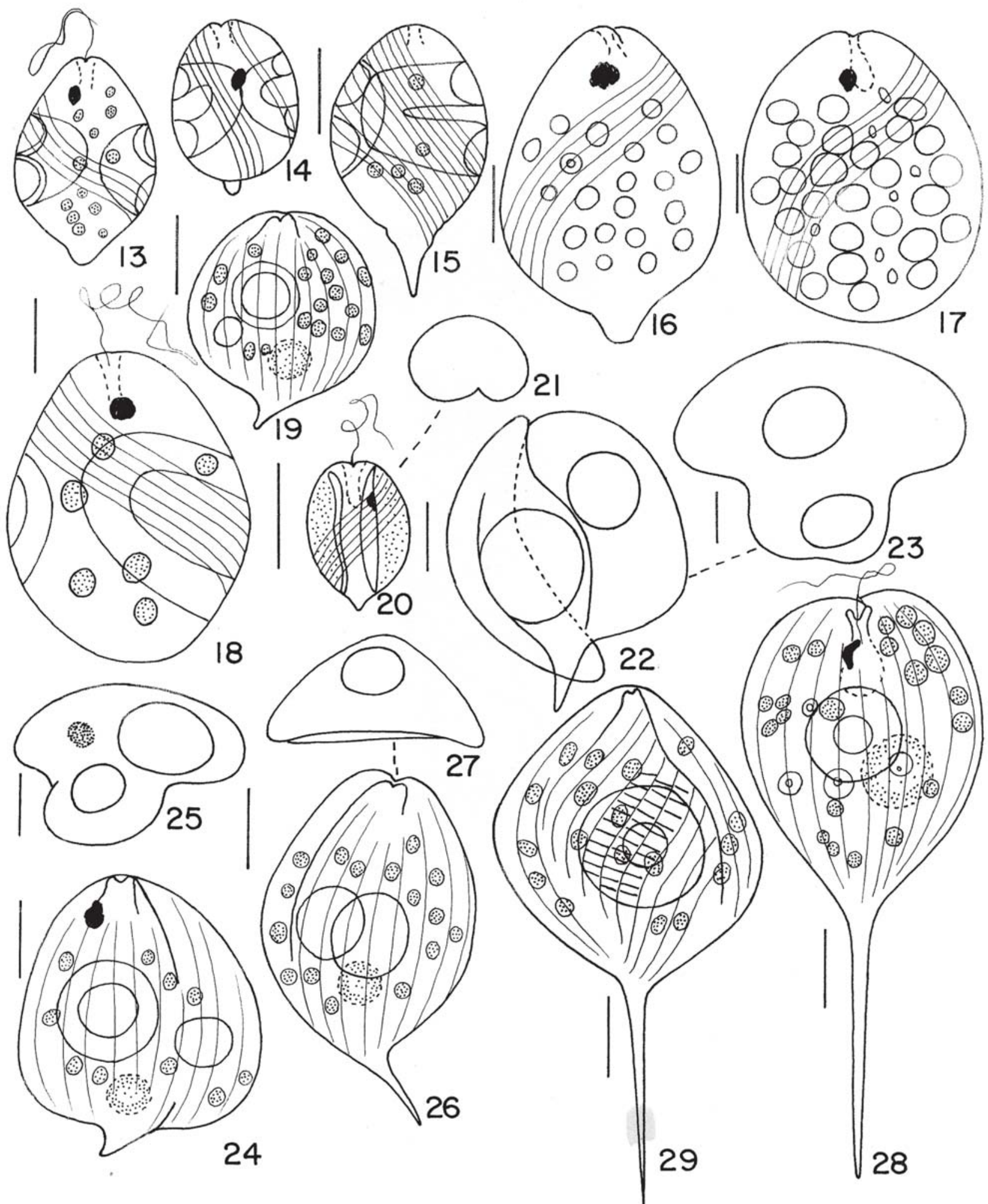

Figuras 13-29. 13. Lepocinclis fusiformis (Carter) Lemm. emend. Conr. var. fusiformis. 14. L. ovum (Ehr.) Lemm. var. dimidio-minor Defl. 15. L. ovum (Ehr.) Lemm. var. ovum. 16. L. salina Fritsch var. salina f. obtusa (Hub.-Pest.) Conr. 17. L salina Fritsch var. salina. 18. L. truncata Da Cunha var. truncata. 19. Phacus acuminatus Stokes var. variabilis (Lemm.) Pochm. 20-21. P. agilis Skuja var. agilis. 21. vista polar. 22-23. P. contortus Bourr. var. contortus. 23. vista polar. 24-25. P. curvicauda Swir. var. curvicauda. 24. vista polar. 26-27. P. hamatus Pochm. var. hamatus. 27. vista polar. 28. P. longicauda (Ehr.) Duj. var. longicauda. 29. P. longicauda (Ehr.) Duj. var. tortus Lemm. Barras $=10 \mu \mathrm{m}$. 
região mediana, estrias transversais entre as longitudinais.

Distribuição geográfica: América do Norte, América do Sul, Ásia, Europa.

Comentários: Goulart et al. 2002 citaram esta variedade como P. tortus (Lemm.) Skv.

23 Phacus orbicularis Hübner var. orbicularis, Prog. Realgym. Stralsund., p. 5, fig. 41. 1896.

Fig. 30-31

Células ovadas, 80-81 $\mu \mathrm{m}$ compr., 44-47 $\mu \mathrm{m}$; Rc/l = 1,6-1,7; pólo anterior arredondado; vista polar transversal triangular, ângulos arredondados; pólo posterior atenuado abruptamente em processo caudal, cônico, de 10-15 um compr.; película com estrias longitudinais e transversais entre as longitudinais; cloroplastos parietais, numerosos, discóides, ca. 2,8 $\mu \mathrm{m}$ diâm.; grãos de paramido 1-2, 1 central, discóide ou anular e outro excêntrico.

Distribuição geográfica: cosmopolita.

24. Phacus raciborskii Drez. var. raciborskii, Kosmos, 50(1 A): 266, pl. 3, fig. 13. 1925.

Fig. 32-33

Células dobradas em forma de sela, ca. de $32 \mu \mathrm{m}$ compr., ca. $14 \mu \mathrm{m}$ larg.; Rc/1 = 2,2; pólo anterior levemente acuminado; vista polar falciforme; lado ventral côncavo, dorsal convexo; quilha arredondada; pólo posterior atenuado em processo caudal hialino, cônico, curvo 5-6 $\mu \mathrm{m}$ compr.; película com estrias longitudinais seguindo a torção da célula; cloroplastos numerosos, discóides; ca. $2 \mu \mathrm{m}$ diâm.; grãos de paramido 2, bastoniformes, tamanhos desiguais, $6 \mu \mathrm{m}$ e 8 um diâm., perpendiculares ao eixo longitudinal da célula.

Distribuição geográfica: cosmopolita.

25. Phacus stokesii Lemm. var. minor Conr., Bull. Mus. Roy. Hist. Nat. Belg. 4: 12, fig. 45-47. 1938. Fig. 34-35
Células amplamente elípticas a levemente ovadas, ca. de $20 \mu \mathrm{m}$ compr., ca. $16 \mu \mathrm{m}$ larg.; Rc/l = 1,2; sulco do vértice ca. 0,8 vez o comprimento da célula; pólo posterior atenuado em processo caudal mamilado; película com estrias longitudinais; cloroplastos numerosos, discóides, grãos de paramido 2, discóides, tamanhos desiguais, 6 um e 8 um diâm.; flagelo duas vezes o comprimento celular.

Distribuição geográfica: América do Sul, Ásia, Europa.

Comentários: esta variedade se distingue da espécie típica pelas menores dimensões celulares. Apesar de Pochmann (1942); Huber-Pestalozzi (1955) e Tell \& Conforti (1986), entre outros citarem a presença de somente um paramido, autores entre os quais Conforti (1994) e Shi et. al. (1999), representam a espécie com dois grãos de paramido, como foi aqui registrado.

26. Phacus undulatus (Skv.) Pochm. var. undulatus, Arch. Protistenk., 95(2): 191, fig. 95-96. 1942.

Fig. 36

Células ovadas, assimétricas, com reentrâncias marginais na película; $72-75 \mu \mathrm{m}$ compr., 46-49 $\mu \mathrm{m}$ larg.; $\mathrm{Rc} / 1=1,5$; pólo anterior arredondado, pólo posterior atenuado abruptamente em processo caudal agudo, fortemente inclinado, com até $16 \mu \mathrm{m}$ compr.; película com estrias longitudinais; grãos de paramido 2, excêntricos; cloroplastos numerosos, discóides, $5 \mu \mathrm{m}$ diâm.; núcleo central, flagelo ca. 0,5 vez o comprimento celular.

Distribuição geográfica: América do Norte, América do Sul, Ásia, Europa.

Comentários: tal como foi registrado no Rio Grande do Sul por Alves-da-Silva \& Bridi (2004) os indivíduos encontrados apresentaram dimensões próximas do limite máximo da espécie (Pochmann 1942: 50-80 $\mu \mathrm{m}$ compr. por 30-48 $\mu \mathrm{m}$ larg.).

Chave artificial para identificação das espécies e infra-espécies do gênero Strombomonas Deflandre 1930

1. Lóricas com processo caudal

2. Processo caudal cônico desenvolvido

3. Lóricas transversalmente elípticas Strombomonas rotunda var. rotunda

3. Lóricas de forma distinta

4. Lóricas sub-hexagonais ou rombóides

5. Lóricas sub-hexagonais, região mediana com estreitamento Strombomonas girardiana var. girardiana

5. Lóricas rombóides, região mediana angulosa Strombomonas gibberosa var. gibberosa

4. Lóricas elípticas a ovadas 
6. Parede com grânulos e verrugas

7. Lóricas amplamente ovadas

7. Lóricas amplamente elípticas

Strombomonas costata var. costata

6. Parede lisa a levemente escabra

8. Lóricas amplamente elípticas, $68-71 \times 27-29 \mu \mathrm{m}, \mathrm{Rc} / \mathrm{l}=2,5-2,7$

Strombomonas fluviatilis var. levis

8. Lóricas elípticas $25-26 \times 12 \mu \mathrm{m}, \mathrm{Rc} / 1=2-2,1 \ldots \ldots .$. Strombomonas fluviatilis var. fluviatilis

2. Processo caudal arredondado, reduzido Strombomonas scabra var. ovata f. minor

1. Lóricas sem processo caudal Strombomonas borystheniensis var. borystheniensis

27. Strombomonas borystheniensis (Roll) Pop. var. borystheniensis, Flora plant. Cryptog. 3(1): 206, pl. 20, fig 15. 1966.

Fig. 37

Lóricas oblongas ou amplamente elípticas,

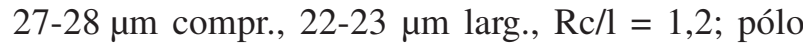
anterior terminando em colarinho baixo, oblíquo, bordo crenulado ca. $7 \mu \mathrm{m}$ larg. e 1,8-2,0 $\mu \mathrm{m}$ alt.; pólo posterior arredondado; parede espessa, granulosa ou rugosa, coloração castanho claro a médio; cloropastos discóides ou bastoniformes com até $5 \mu \mathrm{m}$ diâm.; pirenóides internos.

Distribuição geográfica: América do Sul, Ásia, Europa.

28. Strombomonas costata Defl. var. costata, Arch. Protistenk. 69(3): 589, fig. 76-80. 1930.

Fig. 38

Lóricas elípticas a ovadas, 54-56 $\mu \mathrm{m}$ compr., 27-30 $\mu \mathrm{m}$ larg., Rc/1 = 2,2-2,3; pólo anterior gradativamente atenuado em colarinho cilíndrico, alargado, na extremidade, bordo crenulado $6,5-8 \mu \mathrm{m}$ alt. e 8-9 $\mu \mathrm{m}$ larg.; pólo posterior abruptamente atenuado em processo caudal hialino, cônico, reto e levemente curvado 12-14 $\mu$ m compr.; parede hialina a castanho-avermelhada, levemente rugosa; cloroplastos numerosos, grandes.

Distribuição geográfica: América do Sul, Europa.

Comentários: Conforti (com. person.) comentou que muitos dos indivíduos encontrados na Argentina não apresentaram reentrâncias lobuladas em vista apical, tal como foi observado no presente estudo, diferente do que foi descrito por Deflandre (1930).

29. Strombomonas fluviatilis (Lemm.) Defl. var. fluviatilis, Arch. Protistenk. 69(3): 580, fig. 52-53. 1930.

Fig. 39

Lóricas elípticas, 25-26 $\mu \mathrm{m}$ compr., ca. $12 \mu \mathrm{m}$ larg., $\mathrm{Rc} / 1=2,0-2,1 ;$ pólo anterior gradativamente atenuado em colarinho cilíndrico, levemente reto, bordo liso ou crenulado, 3-4 $\mu \mathrm{m}$ alt. e 4,6-5 $\mu \mathrm{m}$ larg.; vista polar circular; pólo posterior atenuado em processo caudal cônico, reto 3-5 $\mu \mathrm{m}$ compr.; parede granulosa, castanho-avermelhado; cloropastos numerosos, discóides, ca. de 1,5 $\mu \mathrm{m}$ diâm.; grãos de paramido numerosos, bastoniformes; com ou sem pirenóides internos.

Distribuição geográfica: cosmopolita.

30. Strombomonas fluviatilis (Lemm.) Defl. var. levis (Lemm.) Skv., Aus der Biol. Sungari Station zur Harbin 1(2): 78, pl. 6, fig. 33. 1925.

Fig. 40

Lóricas elípticas 68-71 $\mu \mathrm{m}$ compr., 27-29 $\mu \mathrm{m}$ larg., $\mathrm{Rc} / \mathrm{l}=2,5-2,7$.

Distribuição geográfica: cosmopolita.

Comentários: esta variedade difere da típica pelas maiores dimensões celulares.

31. Strombomonas gibberosa (Playf.) Defl. var. gibberosa, Arch. Protistenk. 69(3): 593, fig. 96-103. 1930.

Fig. 41

Lóricas rombóides, região mediana alargada a mais

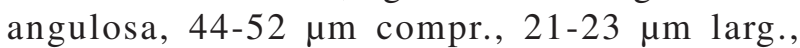
$\mathrm{Rc} / 1=2,0-2,2$; pólo anterior atenuando abruptamente em colarinho cilíndrico, levemente dilatado na extremidade, 8,5-11 $\mu \mathrm{m}$ alt., $6 \mu \mathrm{m}$ larg.; pólo posterior atenuado em processo caudal cônico ca. 15 m compr.; parede castanho avermelhada média; cloroplastos numerosos, discóides, ca. 4 um diâm.

Distribuição geográfica: cosmopolita.

32. Strombomonas girardiana (Playf.) Defl. var. girardiana, Arch. Protistenk. 69(3): 573, fig. 33-35. 1930.

Fig. 42

Lóricas sub-hexagonais, lados quase paralelos, levemente aconcavados na região mediana, $50 \mu \mathrm{m}$ compr., 25 m larg., Rc/1 = 2,0; vista polar circular; 
pólo anterior terminando em colarinho curto, largo, ca. $5,0 \mu \mathrm{m}$, reto ou oblíquo, bordo crenulado; pólo posterior atenuado em processo caudal cônico, reto, ca. $14 \mu \mathrm{m}$ compr.; parede granulosa, hialina a marrom-clara; cloroplastos arredondados ou alongados, ca. 4,5 $\mu \mathrm{m}$ diâm.; pirenóides internos presentes.

Distribuição geográfica: cosmopolita.

33. Strombomonas rotunda (Playf.) Defl. var. rotunda, Arch. Protistenk. 69(3): 593, fig. 88, 1930. Fig. 43

Lóricas com região mediana transversalmente elíptica, 26-29 $\mu \mathrm{m}$ compr., 17-18 $\mu \mathrm{m}$ larg., $\mathrm{Rc} / 1=1,5-1,7$; pólo anterior atenuado abruptamente em colarinho cilíndrico, com bordo reto ou levemente oblíquo, liso ou crenulado, com 4-5 $\mu$ m alt. e $4 \mu \mathrm{m}$ larg.; vista polar circular; pólo posterior abruptamente atenuado em processo caudal agudo, reto, de 8-9 $\mu \mathrm{m}$ compr.; parede rugosa, castanho-clara a avermelhada, cloroplastos discóides.

Distribuição geográfica: América do Norte, América do Sul, Ásia, Oceania.

34. Strombomonas scabra (Playf.) Tell \& Conf. var. ovata (Playf.) Tell \& Conf. f. minor Tell \& Conf., Nova Hedwigia 46(3-4): 546, pl. 2, fig. 2-3, pl. 6, fig. 11-12. 1988 .

Fig. 44-45
Lóricas elípticas, alargadas na região mediana,

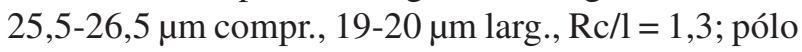
anterior levemente atenuado, terminando em colarinho cilíndrico, levemente curto, bordo crenulado 2,5-3,0 $\mu \mathrm{m}$ alt. e 3-4 $\mu \mathrm{m}$ larg.; vista polar circular; pólo posterior acuminado ca. 2,5 $\mu \mathrm{m}$ compr.; parede espessa, granulosa, castanho-avermelhada; cloroplastos numerosos, discóides; pirenóides internos.

Distribuição geográfica: América do Sul.

Comentários: os exemplares se apresentaram ligeiramente mais largos do que os encontrados na Argentina por Tell \& Conforti (1988), que citam dimensões entre 17-26 $\mu \mathrm{m}$ compr., 10-16 $\mu \mathrm{m}$ larg.

35. Strombomonas verrucosa (Daday) Defl. var. verrucosa, Arch. Protistenk. 69(3): 566, fig. 6-10. 1930.

Fig. 46-47

Lóricas elípticas a ovadas, 55,5-67 $\mu \mathrm{m}$ compr., 24,5-30 $\mu \mathrm{m}$ larg., Rc/1 = 2,0-2,2; vista polar circular; pólo anterior atenuado gradativamente, em colarinho cilíndrico, reto truncado-oblíquo, bordo liso ou crenulado; pólo posterior atenuado em processo caudal cônico, reto ca. $12 \mu \mathrm{m}$ compr.; parede rugosa a granulosa, desde amarelada a castanho-avermelhada; cloroplastos numerosos, discóides, ca. 4 m diâm.; pirenóides internos; grãos de paramido numerosos, bastoniformes ou elípticos.

Distribuição geográfica: cosmopolita.

Chave artificial para identificação das espécies e infra-espécies do gênero

Trachelomonas Ehrenberg emend. Deflandre 1926

1. Lórica com colarinho

2. Colarinho curvo

3. Lóricas elípticas, com espinhos cônicos distribuídos em toda superfície

Trachelomonas similis var. spinosa

3. Lóricas elíptico-oblongas ou oblongas, sem espinhos .... Trachelomonas planctonica var. flexicollis

2. Colarinho não curvo

4. Lóricas elípticas, colarinho com bordo crenulado ou com espinhos

Trachelomonas hispida var. crenulatocollis

4. Lóricas subesféricas, colarinho reto, cilíndrico com espessamento basal

Trachelomonas recticollis var. recticollis

1. Lórica sem colarinho

5. Lóricas lisas

6. Lóricas oblongas, pólo anterior levemente achatado

Trachelomonas oblonga var. truncata

6. Lóricas esféricas

7. Com 2 cloroplastos em escudo e duplopirenóides

Trachelomonas volvocina var. volvocina

7. Com vários cloroplastos sem pirenóides

Trachelomonas volvocinopsis var. volvocinopsis

5. Lóricas ornamentadas

8. Com espinhos

9. Espinhos em toda extensão da lórica 
10. Lóricas amplamente elípticas, (18,5-20×16-17 $\mu \mathrm{m})$, espinhos cônicos curtos Trachelomonas hispida var. hispida f. minor

10. Lóricas cilíndricas, espinhos cônicos curtos, 6-8 pirenóides internos

Trachelomonas lacustris var. lacustris

9. Espinhos somente nos pólos ou de diferentes dimensões

11. Com espinhos cônicos, grandes, convergentes no pólo posterior, lórica ovada

Trachelomonas armata var. steinii

11. Com espinhos cônicos somente nos pólos, lórica elíptica ...Trachelomonas hispida var. duplex 8. Sem espinhos

12. Lóricas esféricas com depressões isodiamétricas

12. Lóricas estreitamente elípticas, pontuada Trachelomonas sculpta var. sculpta Trachelomonas pulcherrima var. minor

36. Trachelomonas armata (Ehr.) Stein var. steinii Lemm. emend. Defl., Revue gén. Bot., 38: 690, pl. 6, fig. 314, 316, 322-324, 326-327, 1926.

Fig. 48

Lóricas ovadas até amplamente ovadas, 33-35 $\mu \mathrm{m}$ compr., 23-24 $\mu \mathrm{m}$ larg., Rc/1 = 1,4-1,5; pólos arredondados, poro flagelar $5 \mu \mathrm{m}$ diâm., espessamento anelar presente, colarinho ausente, parede castanhoavermelhado médio a escuro, pontuada, espinhos menores no pólo anterior; maiores, curvados, algo convergentes, até ca. $5 \mu \mathrm{m}$ compr. no posterior; cloroplastos discóides, algumas vezes poligonais, margens irregulares, ca. 2,5 $\mu$ m diâm.; flagelo ca. 0,8 vez o comprimento da lórica.

Distribuição geográfica: cosmopolita.

Comentários: difere da variedade típica pela presença de espinhos pequenos no pólo anterior, e espinhos maiores convergentes no pólo posterior.

37. Trachelomonas hispida (Perty) Stein emend. Defl. var. crenulatocollis (Maskell) Lemm., Kryptogamenfl. Bradenburg, 3: 526, 1910.

Fig. 49

Lóricas elípticas, 30-33 $\mu \mathrm{m}$ compr., 22-23 $\mu \mathrm{m}$ larg., $\mathrm{Rc} / \mathrm{l}=1,4-1,5$; pólos arredondados, poro flagelar ca. $2 \mu \mathrm{m}$ diâm., espessamento anelar presente, colarinho ca. $2 \mu \mathrm{m}$ alt., 3,5 $\mu \mathrm{m}$ larg., parede castanhoavermelhado, espinhos cônicos, distribuídos por toda superfície da lórica, ca. de 1,5 $\mu \mathrm{m}$ compr.; cloroplastos elípticos, numerosos; duplopirenóides presentes.

Distribuição geográfica: cosmopolita.

38. Trachelomonas hispida (Perty) Stein emend. Defl. var duplex Defl., Révue gén. Bot., 38: 652, pl. 3, fig. 224-226. 1926.

Fig. 51

Lóricas elípticas, 27-31 $\mu$ m compr., 20-22,5 $\mu \mathrm{m}$ larg.; $\mathrm{Rc} / 1=1,3-1,4$, pólos arredondados, poro flagelar e espessamento anelar presentes; colarinho ausente; parede pontuada, castanho-avermelhada, espinhos cônicos, situados apenas nos pólos, ca. 1,8 $\mu$ m compr.; cloroplastos 8-13, discóides, ca. $3 \mu \mathrm{m}$ diâm.; grãos de paramido numerosos, elípticos; duplopirenóides presentes.

Distribuição geográfica: cosmopolita.

Comentários: difere da espécie típica por apresentar espinhos somente nos pólos.

39. Trachelomonas hispida (Perty) Stein emend. Defl. var. hispida f. minor Bour., Soc. Edit. Enseig.: 183, pl. 23, fig. 316. 1952.

Fig. 50

Lóricas amplamente elípticas, 18,5-20 $\mu$ m compr., 16-17 $\mu \mathrm{m}$ larg., $\mathrm{Rc} / \mathrm{l}=1,1-1,3$, pólos arredondados, poro flagelar ca. 3 um diâm., espessamento anelar presente, colarinho ausente; parede castanho-avermelhada, pontuada, espinhos cônicos, distribuídos em toda superfície da lórica, ca. $2 \mu \mathrm{m}$ compr., cloroplastos numerosos, discóides, ca. 1,5 $\mu \mathrm{m}$ diâm.; pirenóides internos; grãos de paramido numerosos, elípticos.

Distribuição geográfica: América Central, América do Sul, Ásia.

Comentários: esta forma se distingue da típica pelas menores dimensões celulares.

40. Trachelomonas lacustris Drez. var. lacustris, Kosmos, 50: 217, pl. 2, fig. 67, 1925.

Fig. 52

Lóricas cilíndricas, 30-31 $\mu \mathrm{m}$ compr., 14-15 $\mu \mathrm{m}$ larg.; $\mathrm{Rc} / \mathrm{l}=2,1$; pólo anterior arredondado; poro flagelar e espessamento anelar presentes; colarinho às vezes presente, bordo denteado; lados paralelos, pólo posterior levemente acuminado; parede pontuada, castanhoavermelhada, espinhos cônicos, ca. de $1 \mu \mathrm{m}$ compr., distribuídos em toda extensão da lórica; cloroplastos discóides, ca. 1,5 بm diâm.; 6-8 pirenóides internos. 


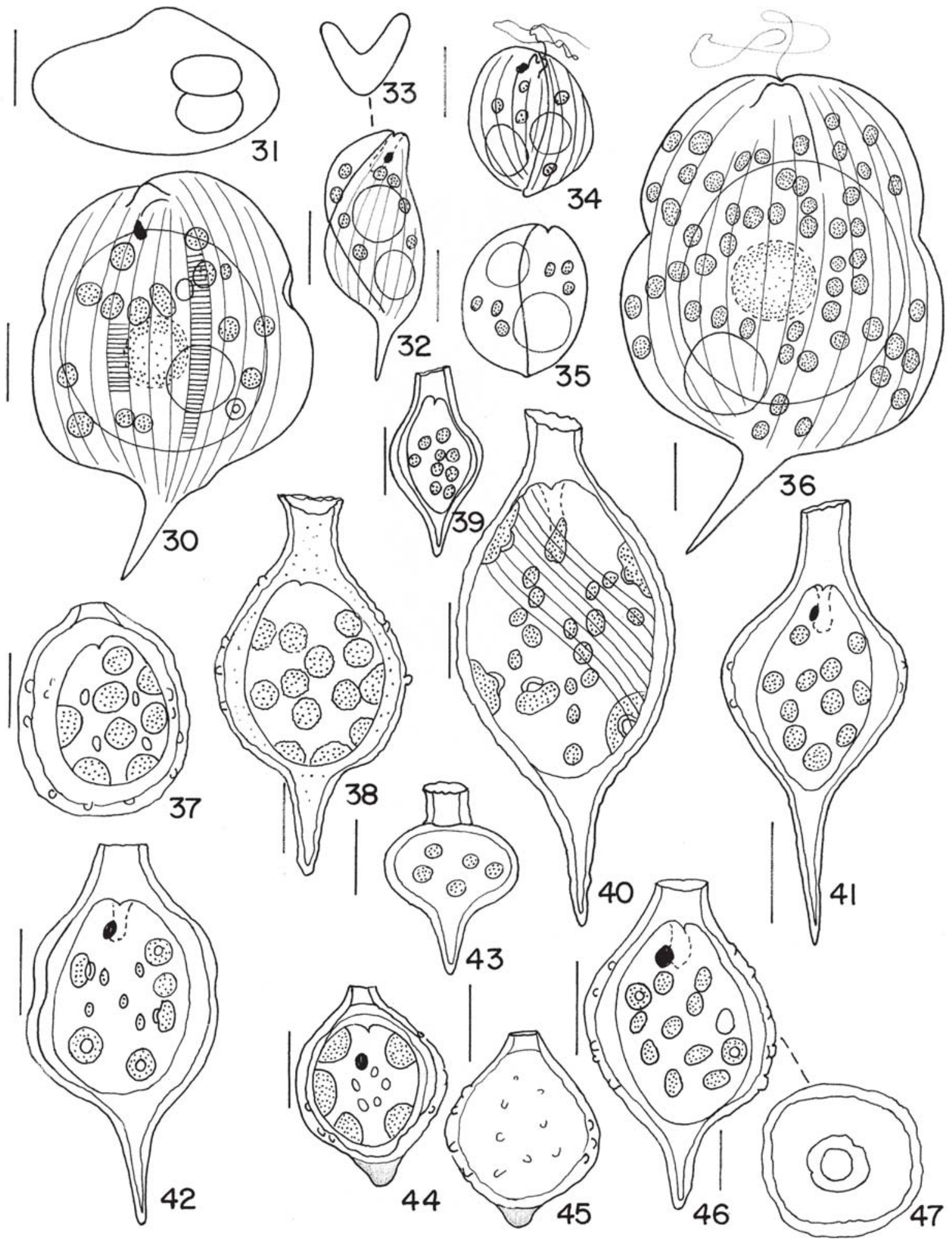

Figuras 30-47. 30-31. P. orbicularis Hübner var. orbicularis. 31. vista polar. 32-33. P. raciborskii Drez. var. raciborskii. 33. vista polar. 34-35. P. stokesii Lemm. var. minor Conr. 36. P. undulatus (Skv.) Pochm. var. undulatus. 37. Strombomonas borystheniensis (Roll) Pop. 38. S. costata Defl. var. costata 39. S. fluvialitis (Lemm.) Defl. var. fluvialitis. 40. S. fluviatilis (Lemm.) Defl. var. levis (Lemm.) Skv. 41. S. gibberosa (Playf.) Defl. var. gibberosa. 42. S. girardiana (Playf) Defl. var. girardiana. 43. S. rotunda (Playf.) Defl. var. rotunda. 44-45. S. scabra (Playf.) Tell \& Conf. var. ovata (Playf.) Tell \& Conf. f minor Tell \& Conf. 46-47. S. verrucosa (Daday) Defl. var. verrucosa. Barras $=10 \mu \mathrm{m}$. 
Distribuição geográfica: cosmopolita.

41. Trachelomonas oblonga Lemm var. truncata, Abh. Nat. Ver. Bremen 16: 344, 1900.

Fig. 53-54

Lóricas amplamente elípticas, 10-10,5 $\mu \mathrm{m}$ compr., 7-9 $\mu \mathrm{m}$ larg.; Rc/l = 1,1-1,2; pólo anterior levemente achatado e posterior arredondado; poro flagelar ca. 1,5 um diâm., espessamento anelar presente, colarinho ausente; parede lisa, castanho-avermelhada média; cloroplastos não observados, 2-4 pirenóides internos.

Distribuição geográfica: cosmopolita.

Comentários: difere da espécie típica pelo pólo anterior mais achatado, posterior geralmente arredondado e pelas menores dimensões celulares.

42. Trachelomonas planctonica Swir. var. flexicollis Bal., An. Mus. Argent. Cienc. Nat., 41: 279, fig. 103, 211. 1944.

Fig. 55

Lóricas elíptico-oblongas a oblongas, ca. $28 \mu \mathrm{m}$ compr., 18-21 $\mu \mathrm{m}$ larg.; Rc/l = 1,5; poro flagelar ca. $3 \mu \mathrm{m}$ diâm., espessamento anelar presente; colarinho cilíndrico, curvo, bordo irregularmente denteado, 3,5-5 $\mu \mathrm{m}$ alt., $5 \mu \mathrm{m}$ larg.; parede castanho-amarelado a avermelhado escuro, pontuada, levemente rugosa ou granulosa; cloroplastos ca. 3 m diâm., pirenóides internos presentes.

Distribuição geográfica: América do Sul, Europa.

Comentários: difere da variedade típica da espécie pela presença de um colarinho cilíndrico curvo.

43. Trachelomonas pulcherrima Playf. var. minor Playf., Proc. of de Linn. Soc. of New South Wales, 40: 14, pl. 1, fig. 37-38. 1915.

Fig. 56

Lóricas estreitamente elípticas, 15-15,5 $\mu \mathrm{m}$ compr., 8-8,5 $\mu \mathrm{m}$ larg.; Rc/l = 1,7-1,9; poro flagelar ca. de $2 \mu \mathrm{m}$ diâm., espessamento anelar presente; parede pontuada, castanho-avermelhada; cloroplastos numerosos oblongos ca. $2 \mu \mathrm{m}$ diâm.; flagelo ca. uma vez o comprimento da lórica.

Distribuição geográfica: América do Sul, América do Norte, Austrália.

Comentários: difere da variedade típica pelas menores dimensões celulares.

44. Trachelomonas recticollis (Playf.) Defl. var. recticollis, Nemours: 101, fig. 483, 484. 1926.

Fig. 57

Lóricas subesféricas, 22-24 $\mu \mathrm{m}$ compr., 17-19 $\mu \mathrm{m}$ larg.; Rc/l = 1,2-1,3; lisa de contorno quadrangular, com extremo anterior mais largo; poro com colarinho reto, cilindrico, espessamento basal, $2 \mu \mathrm{m}$ alt., 2,5-3 $\mu \mathrm{m}$ larg.; pirenóides internos presentes; flagelo até 2 vezes o comprimento da lorica.

Distribuição geográfica: América do Sul, Ásia, Europa, Oceania.

Comentários: táxon facilmente identificado pela morfologia celular e pelo colarinho cilíndrico reto, com espessamento basal.

45. Trachelomonas sculpta Bal. var. sculpta, An. Mus. argent. Cienc. nat., 41: 245, fig. 32, 167, 1944. Fig. 58

Lóricas esféricas, ca. 18 um diâm.; poro flagelar no interior de uma depressão, espessamento anelar presente; colarinho ausente, parede espessa, alaranjada a castanho escura, depressões aproximadamente poligonais, isodiamétricas, densas, regularmente distribuídas em toda superfície da lorica.

Distribuição geográfica: América do Sul e Europa.

46. Trachelomonas similis Stokes var. spinosa Hub.Pest., Phytoplank. Süsswasser, 16(4): 342, pl. 73, fig. 722a, 1955.

Fig. 59

Lóricas elípticas, 30-34 $\mu \mathrm{m}$ compr., $22 \mu \mathrm{m}$ larg.; $\mathrm{Rc} / \mathrm{l}=1,3-1,5$; pólos arredondados; poro flagelar ca. 4 um diâm.; colarinho cilíndrico, fortemente curvo, bordo irregularmente denteado, $4 \mu \mathrm{m}$ alt., $7 \mu \mathrm{m}$ larg.; parede pontuada, avermelhada a acastanhada, espinhos cônicos, distribuição irregular ca. $2 \mu \mathrm{m}$ compr., cloroplastos 8-10, discóides, ca. 5 um diâm.; duplopirenóides presentes.

Distribuição geográfica: África, América do Norte, América do Sul, Europa.

Comentários: difere da variedade típica pela presença de espinhos distribuídos em toda superfície da lorica.

47. Trachelomonas volvocina Ehr. var. volvocina, Infus., v. 48, pl. 2, fig. 29, 1838.

Fig. 60

Lóricas esféricas, 10-13 $\mu \mathrm{m}$ diâm.; poro flagelar e espessamento anelar presente, colarinho ausente, às vezes baixo; parede lisa, avermelhada; cloroplastos 2 , em escudo, ca. $5 \mu \mathrm{m}$ compr. com duplopirenóides; grãos de grãos de paramido numerosos, elípticos ca. $2 \mu \mathrm{m}$ compr.

Distribuição geográfica: cosmopolita. 
48. Trachelomonas volvocinopsis Swir. var. volvocinopsis, Arch. Hydrobiol. Planktonk., 9: 33, pl. 19, fig. 1-3, 1914.

Fig. 61

Lóricas esféricas, ca. 18 um diâm.; espessamento anelar presente ca. $2 \mu \mathrm{m}$ diâm.; colarinho ausente, parede castanho-avermelhada, lisa, cloroplastos mais de 10, discóides, ca. 3 m diâm.; flagelo ca. 1,5 vezes o comprimento da lorica.

Distribuição geográfica: cosmopolita.

Este estudo vem corroborar com Round (1983) e Wetzel (1993), entre outros, que citam que as Euglenophyta são um grupo de algas que ocorre em ambientes ricos em matéria orgânica e amônia, Estas condições propiciaram a presença de 48 táxons deste grupo de algas, destacando-se ainda a presença de representantes de outros grupos em pequeno número de indivíduos por lâmina (de dois a cinco), da classe Chlorophyceae, como Ankistrodesmus bibraianum (Reinsch) Kors., Ankistrodesmus fusiformis Corda, Botryococcus sp., Dictiosphaerium pulchellum Wood, Crucigenia fenestrata (Schmidle) Schmidle, Eudorina elegans Ehr., Kirchneriella obesa (W.S.) W.S., Monoraphidium nanum (Ettl) Hind., Monoraphidium sp., Pediastrum tetras (Ehr.) Ralfs, Oocystis lacustris Chod., Scenedesmus spp., Volvox sp. Da classe Zygnematophyceae foram

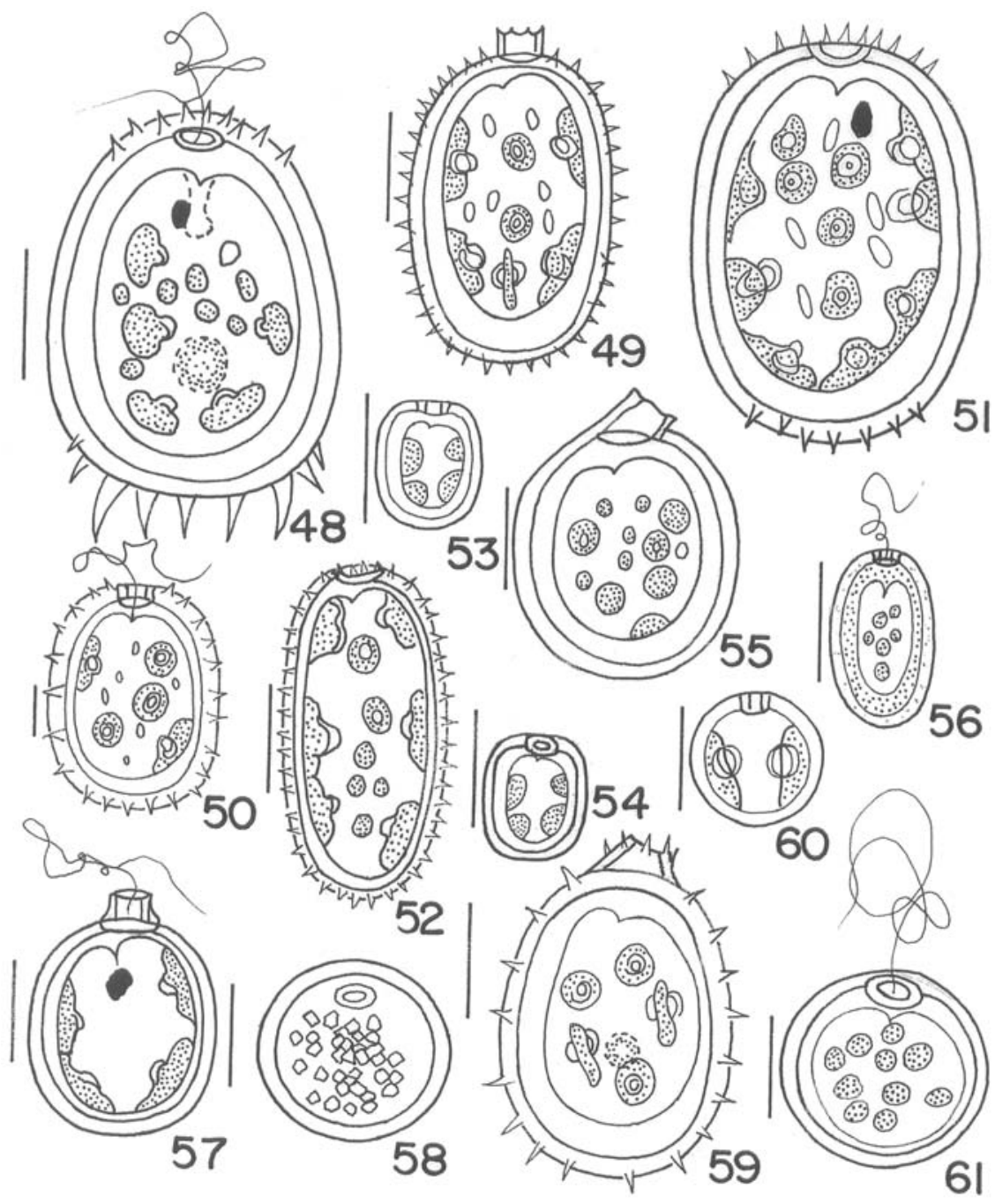

Figuras 48-61. 48. Trachelomonas armata (Ehr.) Stein var. steinii Lemm. emend. Defl. 49. T. hispida (Perty) Stein emend. Defl. var crenulatocollis (Maskell) Lemmm. 50. T. hispida (Perty) Stein emend. Defl. var. hispida f. minor Bourr. 51. T. hispida (Perty) Stein emend. Defl. var. duplex Defl. 52. T. lacustris Drez. var. lacustris. 53-54. T. oblonga Lemm. var. truncata. 55. T. planctonica Swir. var. flexicollis Bal. 56. T. pulcherrima Playf. var. minor Playf. 57. T. recticollis (Playf.) Defl. var. recticollis. 58. T. sculpta Bal. var. sculpta. 59. T. similis Stokes var. spinosa Hub.-Pest. 60. T. volvocina Ehr. var. volvocina. 61. T. volvocinopsis Swir. var. volvocinopsis. Barras $=10 \mu \mathrm{m}$. 
encontrados Arthrodermus octocornis Ehr., Cosmarium spp., Euastrum aff. ansatum Ehr, Pleurotaenium sp., Staurastrum quadrangulare (Bréb.) Ralfs, Staurastrum sp. e Teiligia granulata (Roy et Bisset) Bour. Da classe Bacillariophyceae observou-se Eunotia sp., Navicula sp., Nitzschia sp. e Pinularia braunii (Grun.) Cleve. Dentre as cianobactérias, foi registrado apenas Anabaena sp.

A presença de muitos representantes de Chorophyceae nesse agroecossistema coincide com os resultados encontrados por Heckman et al. (1993) em corpos de água efêmeros, no Pantanal do Mato Grosso, quando também foram encontradas predominantemente espécies de Chlorophyceae e Euglenophyceae.

Florações de Euglena sanguinea foram registradas em tanques de peixes por Xavier et al. (1991) e Zimba et al. (2004) e em arrozais por Pereira et al. (2000) e parcelas experimentais de cultivo de arroz irrigado por Tamanaha (dados não publicados), entre outros estudos. Segundo Zimba et al. (2004) florações de Euglena sanguinea em ambientes com criação de peixes podem levar a grandes perdas econômicas, visto que esta alga foi citada por estes autores como possuindo a capacidade de produzir ictiotoxinas, possivelmente uma neurotoxina a qual foi caracterizada através do nado errático de peixes. Esta informação se reveste de grande importância visto que a rizipiscicultura no estado de Santa Catarina está em crescente desenvolvimento, sendo importante o monitoramento destas florações.

Estudos taxonômicos envolvendo as Euglenophyceae em ambientes temporários como o são arrozais são muito escassos na América do Sul, podendo-se citar Pereira et al. (2000) e Tamanaha (dados não publicados), sendo que este último autor trabalhou em parcelas experimentais de cultivo de arroz irrigado. É interessante observar que Pereira et al. (2000) encontrou em arrozais chilenos (ambiente com profundidade máxima de $15 \mathrm{~cm}$ ), sete táxons também registrados no presente trabalho.

Poucos estudos foram realizados enfocando as Euglenophyta no Estado de Santa Catarina, o trabalho de dissertação de Tamanaha (dados não publicados) trouxe um grande aporte ao conhecimento deste grupo de algas, com a citação de 29 táxons de Euglenophyceae.

Constatou-se que 54,2\% dos táxons identificados possuem ampla distribuição mundial (26 táxons são cosmopolitas) e 45,8\% tem distribuição registrada (22 táxons) a, no máximo, quatro continentes. Apenas um táxon, Strombomonas scabra var. ovata f. minor é exclusivo da América do Sul.

Este estudo vem contribuir no conhecimento das Euglenophyceae em Santa Catarina e também para o incremento da distribuição geográfica destas algas no Brasil, visto que Euglena acus var. longissima, Euglena allorgei var. allorgei, E. caudata, E. spirogyra var. spirogyra, E. spirogyra var. fusca, L. truncata, Phacus acuminatus var. variabilis, $P$. raciborskii var. raciborskii, $P$. stokesii var. minor, P. undulatus var. undulatus, Strombomonas borystheniense, S. fluviatilis var. levis, S. gibberosa var. gibberosa, S. girardiana var. girardiana, $S$. rotunda var. rotunda, S. scabra var. ovata f. minor, T. armata var. steinii, T. hispida var. crenulatocollis, T. hispida var. duplex, T. hispida var. minor, T. lacustris var. lacustris, T. oblonga var. truncata, T. planctônica var. flexicollis, T. pulcherrima var. minor, T. similis var. spinosa, $T$. recticollis var. recticollis e $T$. sculpta são novas citações de ocorrência para este estado.

O grande número de citações novas para o Estado de Santa Catarina $(56,2 \%)$ dentre os 48 táxons descritos neste trabalho, mostra a necessidade de estudos florísticos de Euglenophyta serem incentivados na região.

\section{Agradecimentos}

A Rejane Rosa, pela cobertura à nanquim dos desenhos; ao Dr. Charrid Resgalla Júnior, ao Dr. José Alberto Noldin; a Dra. Cláudia Omachi, pelo auxílio na tradução do resumo e Fundagro pelo apoio.

\section{Referências bibliográficas}

Alves-da-Silva, S.M. \& Bicudo, C.E.M. 2002. Contribution to the knowledge of genus Lepocinclis (Euglenophyceae) of the state of Rio Grande do Sul, Southern Brazil. Algological Studies 106: 77-97.

Alves-da-Silva, S.M. \& Bridi, F.C. 2004. Estudo de Euglenophyta no Parque Estadual Delta do Jacuí, Rio Grande do Sul, Brasil. 2. Os gêneros Phacus Dujardin e Hyalophacus (Pringsheim) Pochmann. Iheringia 59: 75-96.

Alves-da-Silva, S.M. \& Hahn, A. 2004. Study of Euglenophyta in the Jacuí Delta State Park, Rio Grande do Sul, Brasil. 1. Euglena Ehr., Lepocinclis Perty. Acta Botanica Brasilica 18: 123-140.

Alves-da-Silva, S.M. \& Torres, J.R. 1992. Estudo do gênero Lepocinclis Perty (Família Euglenaceae), Parque Zoológico de Sapucaia do Sul e Jardim Botânico de Porto Alegre, Rio Grande do Sul, Brasil. Iheringia 42: 87-104. 
Alves-da-Silva, S.M. \& Torres, J.R. 1994. O gênero Euglena Ehr. de sistema lênticos do Parque Zoológico e Jardim Botânico, Rio Grande do Sul, Brasil. Revista Brasileira de Biologia 54: 345-363.

Cecy, I.I.T. 1990. A restinga do Pontal do Sul, município de Paranaguá, Pr. - I. Levantamento ficológico (Euglenophyta) e físico-químico. Arquivos de Biologia e Tecnologia 33: $1-79$.

Conforti, V.T.D. 1994. Study of the Euglenophyta from Camaleão Lake (Manaus, Brazil). III. Euglena Ehr., Lepocinclis Perty, Phacus Duj. Revue Hydrobiologique tropicale 27: 3-21.

Conrad, W. 1943. Remarques sur le genre Phacus. Bulletin du Musée Royal d'histoire naturelle de Belgique 19: 1-16.

Conrad, W. \& Van-Meel, L. 1952. Materiaux pour une monographie de Trachelomonas Ehrenberg. C. (1834): Strombomonas Deflandre. G. (1930): et Euglena Ehrenberg C. (1832): genres d'Euglénacées. Mémoires d l'Institute Royal des Sciences Naturelle Belgique 124: 1-176.

Deflandre, G. 1926. Monographie du genre Trachelomonas Ehrenberg. Nemours, André Lesot.

Deflandre, G. 1930. Strombomonas, nouveaux genre d’Euglenacées (Trachelomonas Ehr. pro parte). Archiv für Protistenkunde 69: 551-614.

Epagri. 1998. Sistema de produção de arroz irrigado em Santa Catarina: (Pré-Germinado). EPAGRI Florianópolis.

Ferreira, A.C.S. \& Menezes, M. 2000. Flora planctônica de um reservatório eutrófico, lagoa Guandu, município de Nova Iguaçu, RJ. Hoehnea 27: 45-76.

Furtado, R.D. \& De Luca, S.J. 2003. Técnicas de Cultivo de arroz irrigado: Relação com a qualidade de água, protozoários e diversidade fitoplanctônica. Revista Brasileira de Engenharia Agrícola e Ambiental 7: 165-172.

Goulart, E.; Couté, A.; Thérézien, Y. \& Franceschini, I.M. 2002. Phytoplankton of lentic water from the Campus of Santa Catarina University (Florianópolis, SC, Southern Brazil). Ciência \& Natura 24: 21-48.

Gojdics, M. 1953. The genus Euglena. Madison, The University of Wisconsin Press.

Heckman, C.W.; Hardoim, E.L.; Ferreira, S.A. \& Kretzschmar, A.U. 1993. Prelimary observations on some cosmopolitan algae in ephemeral water bodies of the Pantanal, Mato Grosso, Brasil. In: B. Gopal; Hillbricht-Ilkowska; R.G. Wetzel. Wetlands and Ecotones: studies on land-water interactions. New Delhi, National Institute of Ecology/ International Scientific Publ.

Huber-Pestalozzi, G. 1955. Euglenaceen. In: Das phytoplankton des Susswässers. Systematik und Biologie, Stuttgart, E. Schweizerbart'sche Verlangsbuchhandlug. (Die Binnengewässer, August Thienemann, 16).

Jati, S. \& Train, S. 1994. Euglenaceae pigmentadas de ambientes lênticos da ilha Porto Rico, município de Porto Rico, Paraná, Brasil. Iheringia 45: 117-142.

Mainardes-Pinto, C.S.R. \& Mercante, C.T.J. 2003. Avaliação de variáveis limnológicas e suas relações com uma floração de Euglenaceae pigmentada em viveiro povoado com tilápia do Nilo (Oreochromis niloticus Linnaeus), São Paulo, Brasil. Acta Scientiarum Biological Sciences 25: 323-328.
Menezes, M. 1989. Contribuição ao conhecimento de algas pigmentadas do gênero Euglena (Euglenophyceae) no município do Rio de Janeiro e arredores, Brasil. Acta Botanica Brasilica 3: 49-90.

Menezes, M. 1990. Estudos taxonômicos sobre o gênero Lepocinclis Perty (Euglenaceae) no Município do Rio de Janeiro e arredores, Brasil. Revista Brasileira de Biologia 50: 103-113.

Menezes, M. 1991. O gênero Phacus Dujardin (Euglenaceae) no Município do Rio de Janeiro e arredores, Brasil. Hoehnea 18: 171-189.

Menezes, M. \& Fernandes, V.O. 1987. Euglenaceae pigmentadas do município de Cáceres e arredores, Mato Grosso, Brasil: uma contribuição a seu conhecimento. Rickia 14: 53-71.

Németh, J. 1980. Az ostoros Algák (Euglenophyta); Kishatározóija pt.1. Vizdock:Budapeste (Vizügyi Hidrobiológia, 8).

Noldin, A.N.; Eberhardt, D.S.; Deschamps, F.C.; Prando, H.F.; Knoblauch, R.; Resgalla Jr., C.; Sato, G.; Schiocchet, M.A. \& Ishiy, T. 2003. Algumas recomendações para a produção de arroz irrigado com baixo impacto ambiental. (Epagri. Boletim Didático, 52.).

Pereira, I.; Reyes, G. \& Kramm, V. 2000. Cyanophyceae, Euglenophyceae, Chlrophyceae, Zygnematophyceae \& Charophyceae em arrozales de Chile. Gayana: Botánica 57: 29-53.

Pochmann, A. 1942. Synopsis des Gattung Phacus. Archiv für Protistenkunde 5: 121-252.

Roger, P.A.; Heong, K.L. \& Teng, P.S. 1991. Biodiversity and sustainability of wetland rice production: role and potential of microorganisms and invertebrates. In: D.L. Hawksworth (ed.). The biodiversity of microorganisms and invertebrates: its role in sustainable agriculture. Manila, Philippines, CAB International.

Round, F. 1983. Biologia das Algas. 2 ed. Rio de Janeiro, Ed. Guanabara Dois.

Sant'Anna, C.L.; Azevedo, M.T.P. \& Sormus, L. 1989. Fitoplâncton do Lago das Garças, Parque Estadual das Fontes do Ipiranga, São Paulo, SP, Brasil: Estudo taxonômico e aspectos ecológicos. Hoehnea 16: 89-131.

Shi, Z.; Wang, Q.; Xie, S. \& Daí, J. 1999. Euglenophyta. China, Science Press. (Flora Algarum Sinicarum Aquae Dulcis, v. 6).

Starmach, K. 1983. Euglenophyta. In: K. Starmach (ed.). Flora Slodkowodna Polski. 3. Polska Academia Nauk., Warszawa.

Tavares, A.S. 1980/1981. Estudo ficológico do lago da Universidade Federal de Santa Catarina, Florianópolis, Brasil. Ínsula 11: 37-69.

Tell, G. \& Conforti, V.T.D. 1986. Euglenophyta pigmentadas de la Argentina. Stuttgart, J. Cramer. (Bibliotheca Phicologica 75).

Tell, G. \& Conforti, V.T.D. 1988. Quelques Strombomonas Defl. (Euglenophyta) de l'Argentina au microscope photonique et eletrónique à balayage. Nova Hedwigia 46: $541-556$. 
Weik, K.L. 1967. A revision of the genus Phacus Dujardin in Illinois. 237f., il. Tese Doutorado. Illinois, Departamento de Botânica.

Wetzel, R.G. 1993. Limnologia. Trad. Maria José Boavida. Lisboa, Fundação Calouste Gulbenkian. Trad. Limnology.

Wolowski, K. 1998. Taxonomic and environmental studies on Euglenophytes of the Kraków-Szestochowa Upland (Southern Poland). Fragmenta Floristica et Geobotanica 6: 3-192. Suplements.

Xavier, M.B. 1989. O gênero Phacus Dujardin de lagos do Parque Estadual das Fontes do Ipiranga, São Paulo, Brasil. Hoehnea 16: 149-164.
Xavier, M.B. 1996. Fitoplâncton do Rio Grande, Represa Billings. São Paulo, Brasil: estudo taxonômico (19951986). Iheringia 47: 103-122.

Xavier, M.B.; Mainardes-Pinto, C.S.R. \& Takino, M. 1991. Euglena sanguinea bloom in a fish-breeding tank (Pindamonhangaba, São Paulo, Brazil). Algological Studies 62: 133-142.

Zakrýs, B. 1986. Contribution to the monograph of polish members of the Genus Euglena Eh. Nova Hedwigia 42: 491-540.

Zimba, P.V.; Rowan, M. \& Trimer, R. 2004. Identification of euglenoid algae that produce ichthyotoxin (s). Journal of Fish Diseases 27: 115-117. 